\title{
A New Method for the Measurement of Cerebral Blood Volume and Total Circulating Blood Volume Using Near Infrared Spatially Resolved Spectroscopy and Indocyanine Green: Application and Validation in Neonates
}

\author{
TERENCE S. LEUNG, NARENDRA ALADANGADY, CLARE E. ELWELL, DAVID T. DELPY, AND \\ KATE COSTELOE
}

Department of Medical Physics and Bioengineering, University College London, 1st Floor, Shropshire House, 11-20 Capper Street, London WC1E 6JA [T.S.L., C.E.E., D.T.D.]; Department of Child Health, Barts and the London School of Medicine and Dentistry, Homerton University Hospital, London E9 6SR

[N.A., K.C.]

\begin{abstract}
ABST
A new technique known as tissue dye densitometry (TDD)
has been developed to simultaneously measure cerebral blood
volume (CBV) and total circulating blood volume (TCV) using
near infrared (NIR) spatially resolved spectroscopy (SRS) and
the injection of indocyanine green (ICG). Using a medical NIR
spectrometer with SRS capability (NIRO-300, Hamamatsu KK),
a new parameter is calculated known as the $I C G H b$ index $(I H I)$,
which represents the ratio of ICG concentration to Hb concen-
tration in tissue. Acting as a tracer, ICG is cleared by the liver
over 15 min, providing a change of tracer concentration ( $\Delta C_{I C G}$
tis), which allows the calculation of the total Hb concentration in
tissue ( $t c H b)$ using the equation: $t c H b_{t i s}\left(\mu\right.$ molar) $=\Delta C_{I C G, t i s}$
$\Delta I H I$. The CBV can subsequently be calculated from $t c H b_{t i s}$
given the absolute Hb concentration in blood (g/dL), from which
the ICG concentration in blood $\left(\Delta C_{I C G, b l}\right.$ is obtained. By back-
extrapolating the $\Delta C_{I C G, b l}$ curve to the peak time, the initial ICG
concentration in tissue blood $\left(C_{I C G, b l}^{0}\right.$ ) can be found and TCV
can then be calculated. The TCV of 17 neonates were measured
using the TDD technique and for comparison using the previ-
ously reported fetal Hb dilution technique (FHD). The mean
\end{abstract}
TCV measured by the FHD and TDD techniques were $70.19 \pm$ $13.73 \mathrm{~mL} / \mathrm{kg}$ and $70.80 \pm 32.54 \mathrm{~mL} / \mathrm{kg}$. The Bland Altman plot showed that the bias was $0.61 \pm 34.34 \mathrm{~mL} / \mathrm{kg}$ and limits of agreement (2 SD) were $-68.07 \mathrm{~mL} / \mathrm{kg}$ and $69.30 \mathrm{~mL} / \mathrm{kg}$. The agreement is limited and the TDD technique needs further validation and development for use in a clinical environment. (Pediatr Res 55: 134-141, 2004)

$\quad$ Abbreviations
CBV, cerebral blood volume
DPF, differential pathlength factor
FHD, fetal Hb dilution
ICG, indocyanine green
IHI, ICG Hb index
NIR, near infrared
PDD, pulse dye densitometry
SRS, spatially resolved spectroscopy
TCV, total circulating blood volume
TDD, tissue dye densitometry

Achieving a stable circulation in the first hours of life is fundamental to the provision of successful neonatal intensive care. Many clinical studies describe the administration of boluses of fluid to expand the total circulating volume (TCV) in response to clinical signs of poor skin perfusion, hypotension or acidosis and yet studies both in adults and the newborn

Received May 13, 2002; accepted April 17, 2003.

Correspondence: Terence Leung M.D., Department of Medical Physics and Bioengineering, University College London, Shropshire House, 11-20 Capper Street, London WC1E 6JA, UK; e-mail: tsl@medphys.ucl.ac.uk

Funded by a grant from the Wellcome Trust (Grant 054762).

DOI: 10.1203/01.PDR.0000099775.87684.FB show the prediction of hypovolemia by clinical assessment to be poor $(1,2)$. The availability of a simple cotside method to estimate TCV that could be used shortly after birth would be a useful tool both for the neonatal clinician and the researcher. Methods used previously involving the injection of autologous red cells labeled with biotin (3) or repeated blood sampling following injection of a marker such as indocyanine green (4) are not suitable for routine clinical practice.

The technique of Near Infrared (NIR) Spectroscopy is attractive to the neonatologist because of its noninvasive nature. The attenuation signals from a NIRS monitor reflect changes of $\mathrm{Hb}$ concentrations in any of the vascular compartments. Ex- 
amples of this type of instrumentation include the NIRO-300 and 500 (Hamamatsu KK, Japan). These NIR monitors have been applied in the clinical measurement of a number of hemodynamic parameters in the newborn and adult including tissue oxygen saturation $(5,6)$, cerebral blood flow $(7,8)$ and absolute cerebral blood volume $(9,10)$.

To calculate the absolute cerebral blood volume (CBV), the existing techniques require a small change in concentration of an intravascular tracer. The newborn studies have used a change of oxy- $\mathrm{Hb}(9)$ and in a study in adults, indocyanine green has been used (10). The methodology is dependent on knowing the concentration of tracer in the blood while the NIR monitor measures the change in cerebral tissue: in the neonatal studies oxygen saturation measured noninvasively via a pulse oximeter was used while the adult study obtained the ICG elimination curve from repeated venous sampling.

In this paper, a new technique called tissue dye densitometry (TDD) is described which estimates both CBV and TCV from measurements with a NIRS monitor having both difference spectroscopy (11) and Spatially Resolved Spectroscopic (SRS) capabilities (NIRO-300, Hamamatsu KK, Hamamatsu, Japan) $(5,6)$ following a single injection of ICG. This method does not require the use of any direct invasive monitoring of blood tracer levels. Estimates of TCV made using the new method have been compared with simultaneous measurements using the technique proposed by Phillips et al. (12) using the percentage of fetal $\mathrm{Hb}$ before and after a blood transfusion.

\section{METHODS}

The tissue dye densitometry technique. Using SRS, it has been shown that a scaled absorption coefficient can be calculated from the attenuation gradient measurements from multiple, incrementally spaced, detectors $(5,6)$. Subsequently the scaled absorption coefficient can be converted to a scaled value of the chromophore concentration. If absorption due to water and background absorbers is initially ignored (see later), the scaled concentration of three major chromophores, deoxy-Hb $\left(k \cdot \mathrm{C}_{H H b}\right)$, oxy-Hb $\left(k \cdot \mathrm{C}_{\mathrm{HbO} 2}\right)$ and ICG $\left(k \cdot \mathrm{C}_{I C G}\right)$ can be calculated (where $k$ is the unknown scaling factor accounting for scattering in tissues and has the same value for $C_{\mathrm{HHb}}, C_{\mathrm{HbO} 2}$ and $C_{I C G}$ ). An example of the scaled concentration of the three major chromophores is shown in Fig. 1. A new index known as the ICG $\mathrm{Hb}$ Index $(I H I)$ can also be defined as follows:

ICG Haemoglobin Index

$$
(I H I)=\frac{k \cdot C_{I C G}}{k \cdot C_{H H b}+k \cdot C_{\mathrm{HbO}_{2}}}=\frac{C_{I C G}}{C_{H H b}+C_{\mathrm{HbO}_{2}}}
$$

It can be seen in the definition of $I H I$ that the unknown scaling factor $k$ appears as a factor of both the numerator and denominator and thus cancels out. The $I H I$ can be regarded as the ICG concentration per unit concentration of $\mathrm{Hb}$. Using this simple approach, the resulting $I H I$ signal has a negative offset (as shown in Fig. $2 a$ ) because the effects of water and background absorbers have been ignored. The total $\mathrm{Hb}$ concentration in tissue $\left(t c H b^{\prime}\right)$ can be calculated by the linear regression

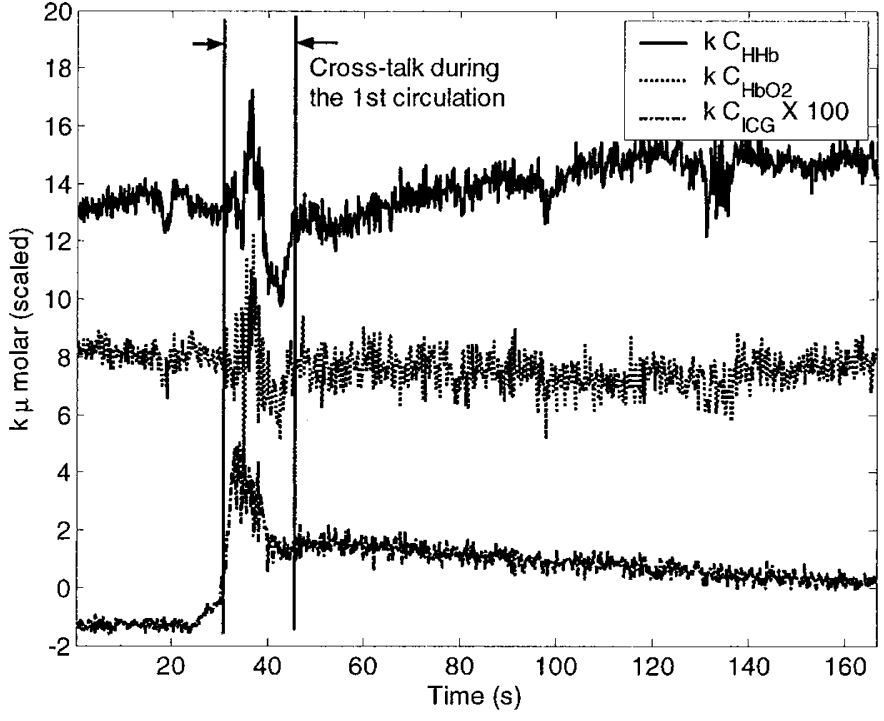

Figure 1. An example recording of the scaled concentrations of the three major chromophores. The high concentration of ICG during the 1st circulation results in some cross-talk between ICG and the $\mathrm{Hb}$ species as marked.
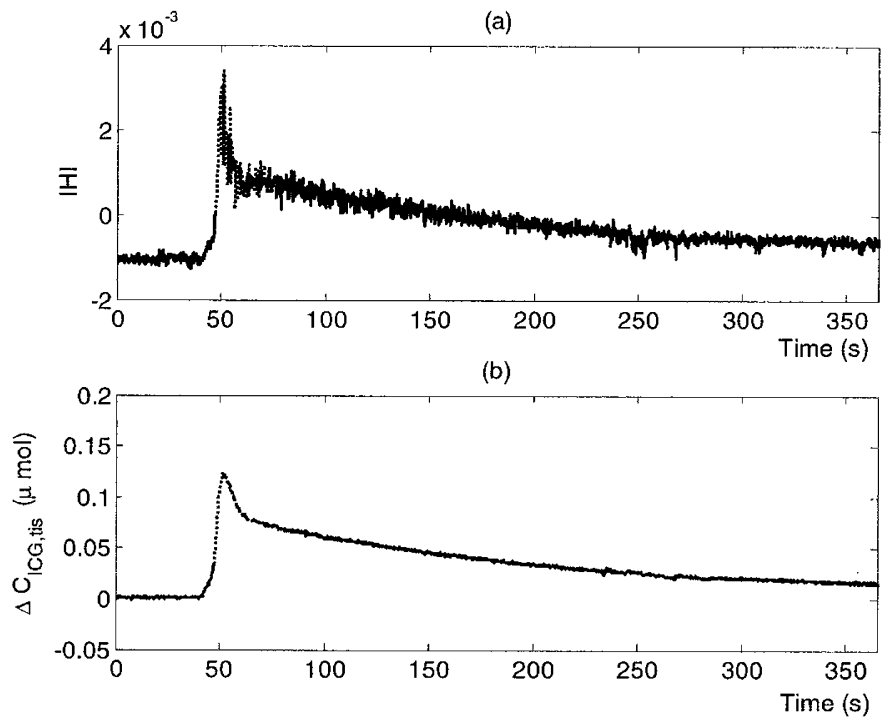

Figure 2. (a) ICG Hb Index (IHI) calculated based on a TDD measurement; (b) Changes of ICG concentration in tissue $\left(\Delta C_{I C G, t i s}\right)$ calculated based on NIR difference spectroscopy; dotted parts (defined from $5 \mathrm{~s}$ before to $25 \mathrm{~s}$ after the peak) was excluded from the linear regression shown in Fig. 3.

between $I H I$ (Fig. 2a) and changes in $\Delta C_{I C G, t i s}$ (Fig. 2b) as shown in Fig. 3:

$$
t c H b^{\prime}=\frac{\Delta C_{I C G, t i s}}{\Delta I H I}
$$

( $\mu$ molar)

where $\Delta C_{I C G}$, tis is the absolute change in ICG concentration calculated using conventional NIR difference spectroscopy. A recent study in rats (13) showed that the extent to which the $\mathrm{Hb}$ signals are affected by cross-talk is related to the ICG dosage. The larger the ICG dosage, the longer the effect of cross-talk in $\mathrm{Hb}$. A low dosage of ICG was used in our study $(0.2 \mathrm{mg} / \mathrm{kg})$ which was even lower than that used in a previous clinical study in humans (10). We observed a small degree of cross-talk between ICG and $\mathrm{Hb}$ species in some subjects during the 1st 


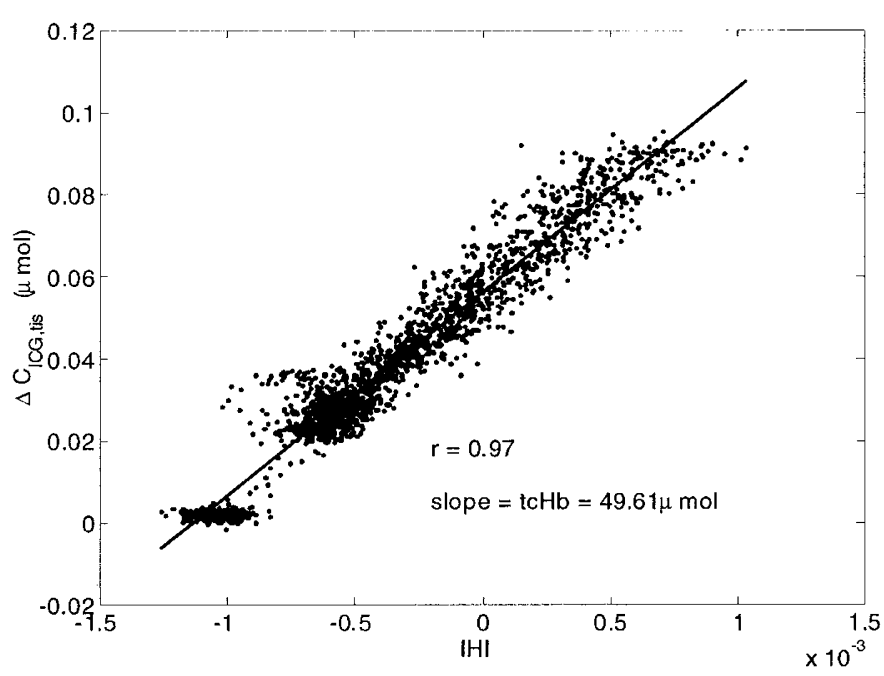

Figure 3. Plotting $\Delta C_{I C G, t i s}$ against $I H I$ : the slope of the linearly regressed straight line $=t c H b$.

circulation when ICG concentration in tissues was relatively high (see Fig. 1 for an example). However, the cross-talk effect on the $\mathrm{Hb}$ signals disappeared approximately $20-30 \mathrm{~s}$ after the initial injection of ICG. This can be seen from Fig. 1 which shows that the cross-talk is only significant between $t=30$ second and $\mathrm{t}=45$ second (injection at $\mathrm{t}=22$ second), after which the levels of the two $\mathrm{Hb}$ species, i.e. $\mathrm{C}_{\mathrm{HHb}}$ and $\mathrm{C}_{\mathrm{HbO} 2}$ return to their original values. To avoid the effect of any cross-talk, the data during the first circulation has been excluded in the linear regression. In the calculation of $\Delta C_{I C G, t i s}$, a constant known as the differential pathlength factor (DPF) has to be taken into account for the additional distance photons have to travel in scattering media (14). The DPF has been previously measured for a range of tissues (15). In this study for the neonatal head, the DPF was set to 5.13. The above equation for $t c H b$ ' is similar to the one used in the oxygen desaturation method of assessing CBV (9) except that here ICG instead of oxy-Hb is being used as the tracer.

The background absorption represents a large and constant value arising from all other chromophores in tissues such as melanin and lipids (but excluding water) etc. Previous studies suggest it accounts for approximately $30 \%$ of the overall absorption coefficient $\left(\mu_{\mathrm{a}}\right)(16,17)$. The proportion of water in cerebral tissue is in the range of $80 \%$ to $90 \%$ by volume (18, 19). Despite its low optical absorption property in the NIR range, this large tissue water content results in its absorption also affecting the measurement of $t c H b$. The background absorption is considered to account for $22 \%$ of the total absorption in this paper and is subtracted from the original absorption coefficient before the conversion to chromophore concentration is performed. To minimize the effect of water, the initially biased $t c H b$ ' is corrected to true $t c H b$ by the subtraction of $15.15 \mu$ molar (see Appendix for details of this correction):

$$
t c H b=t c H b^{\prime}-15.15
$$

( $\mu$ molar)

Once true $t c H b$ is obtained, the CBV can be calculated using the following formula (9):

$$
C B V=\frac{t c H b \cdot M W_{H b} \cdot 10^{-6}}{t H b \cdot 10^{-2} \cdot D_{t} \cdot 10 \cdot C L V H R}
$$

( $\mathrm{ml}$ of blood / $100 \mathrm{~g}$ of tissue)

where $t H b(\mathrm{~g} / 100 \mathrm{~mL})$ is the $\mathrm{Hb}$ concentration in blood obtained from a venous sample, $M W_{H b}=64500 \mathrm{~g} / \mathrm{mol}$ the molecular weight of $\mathrm{Hb}, D \mathrm{t}=1.05 \mathrm{~g} / \mathrm{mL}$ the density of tissue and $C L V H R=0.69$ the cerebral-to-large vessel hematocrit ratio (20). Using conventional NIR difference spectroscopy, the changes in ICG concentration in tissue, i.e. $\Delta C_{I C G, t i s}$, can be measured in units of $\mu$ Mole of ICG/100 g of tissue. Changes in ICG concentration in tissue blood can therefore be calculated by (note the units):

$\Delta C_{I C G, b l}=\frac{\Delta C_{I C G, t i s} \times M W_{I C G}}{C B V} \quad(\mathrm{mg}$ of ICG $/ \mathrm{ml}$ of blood $)$

where $M W_{I C G}=775 \mathrm{~g} / \mathrm{mol}$ is the molecular weight of ICG. The dye concentration in tissue $(\mathrm{mg} / 100 \mathrm{~g})$ is now converted into dye concentration in tissue blood $(\mathrm{mg} / \mathrm{mL})$ and we call this technique tissue dye densitometry (TDD).

Since the ICG is continuously being eliminated by the liver, it is necessary to identify from the clearance curve the point in time when the ICG is fully mixed with blood but not yet eliminated by the liver. It has previously been suggested when using arterial ICG monitoring that a line can be backextrapolated from the exponentially decaying part of the clearance curve to either the time of injection or the mean transit time $(21,22)$ and the corresponding ICG concentration is regarded as the initial fully circulated ICG concentration, i.e. $C^{0}{ }_{I C G, b l}$. The mean transit time is calculated over the first circulation curve starting from the time of injection and is considered as the time when the dye first arrives in the field of view.

In this paper, the time when $C^{0}{ }_{I C G, b l}$ occurs has been chosen as the time when ICG concentration reaches the maximum, i.e. the peak time as shown in Fig. 3. The rationale behind this is that the tissue monitor used here measures ICG concentrations in tissue blood (in contrast to the arterial blood). The peak time is therefore the time at which the largest amount of tracer is in the field of view. To perform the estimate, the clearance curve is first converted into logarithmic scale and then a linear regression is carried out on the section between 1 min and 4 minute after the peak time. By back extrapolating this line to peak time, as shown in Fig. 4, the initial ICG concentration $\left(C^{0}{ }_{I C G, b l}\right)$ can be identified. The total circulating blood volume (TCV) can then be found

$$
T C V_{T D D}=\frac{I C G \text { dose }}{C_{I C G, b l}^{0}} \quad(\mathrm{ml} \text { of blood })
$$

where ICG dose is the amount of ICG injected in mg.

The fetal Hb dilution (FHD) technique. After a blood transfusion, the fetal $\mathrm{Hb}$ is diluted. Knowing the volume of red blood cells being transfused, the $T C V_{F H D}$ pretransfusion can be calculated as follows (12):

$T C V_{F H D}=\frac{V \times H b F_{p o s t} \%}{H c t_{\text {pre }}\left(H b F_{\text {pre }} \%-H b F_{\text {post }} \%\right)} \quad$ (ml of blood $)$ 


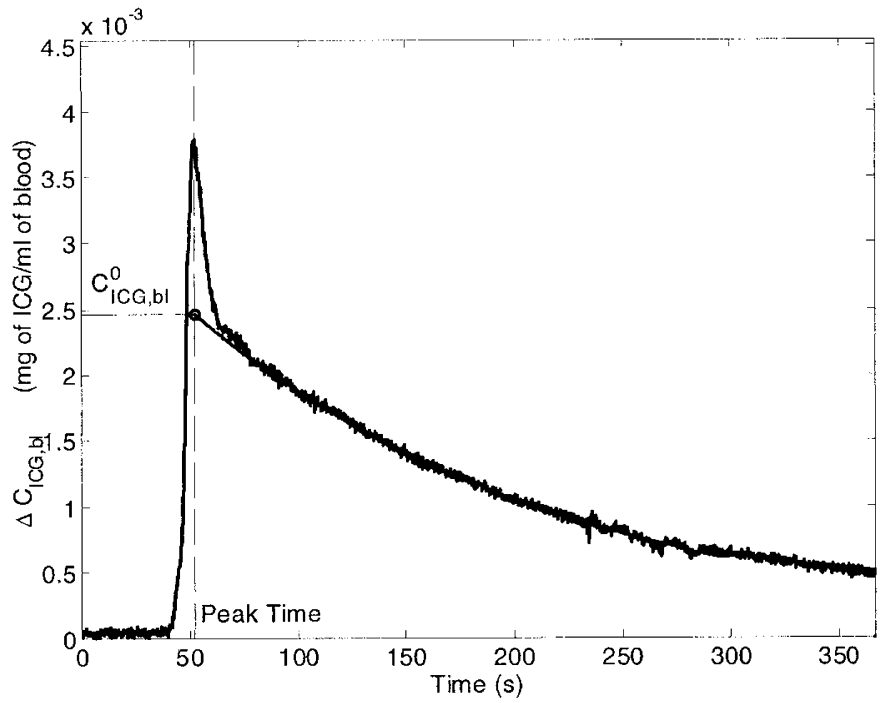

Figure 4. ICG concentration in tissue blood at peak time derived by back-extrapolation.

where $V$ is the volume of red cells transfused in $\mathrm{ml}, \mathrm{HbF}_{\text {pre }} \%$ is the percentage of fetal $\mathrm{Hb}$ before transfusion, $\mathrm{HbF}_{\text {post }} \%$ is the percentage of fetal $\mathrm{Hb}$ after transfusion and $H_{c t} t_{\text {pre }}$ is the pretransfusion hematocrit. Fetal $\mathrm{Hb}$ was measured by HPLC (23) (Varient, Bio-Rad, U.S.A.) and hematocrit was measured by an automated full blood count analyser (Sysmex, SE9500, Japan).

Subjects. The study was approved by the Local Research Ethics Committee of East London and the City Health Authority and infants were studied with informed written consent from the parents. A total of 25 babies were studied. Data from 7 were excluded because of problems with the NIR method: 5 because of poor signal quality secondary to body movement and probe dislodgement and 2 because the first circulation of the tracer could not be seen on the clearance curve. Results from another infant were excluded because of a laboratory accident with the estimation of fetal $\mathrm{Hb}$. Successful paired measurements were made from 17 infants. The median gestational age of these 17 infants was 28 completed weeks, their weight was $1030 \mathrm{~g}$ and the age at testing was 6 days (Table 1). Twelve infants $(70.6 \%)$ were receiving either mechanical ventilation or nasal continuous positive airway pressure and the other five (29.4\%) needed supplementary oxygen at the time of the measurement. All the infants studied had normal $\mathrm{pH}$ and arterial blood pressure. No complication was noted related to either the equipment or ICG injection.

Measurement procedures. Only babies needing blood transfusion for clinical indications were studied and those included in the analysis were all receiving their first transfusion. The NIRO-300 optical probe was attached to the infant's forehead and the initialization of the monitor was performed. A rapid bolus of $0.2 \mathrm{mg} / \mathrm{kg}$ ICG (ICG-Pulsion, Pulsion Medical System AG, Munich, Germany) was injected through an existing umbilical or peripheral venous cannula. The continuous change in ICG concentration was measured noninvasively for $20-30 \mathrm{~min}$ using the NIRO-300. The blood transfusion was started soon after completing the noninvasive measurement of ICG concentration and the donor blood transfused over $3-4 \mathrm{~h}$. Three blood samples were collected, a small donor blood sample for Hct, and two infant samples: $0.5 \mathrm{~mL}$ shortly before the transfusion for $\mathrm{Hb}, \mathrm{Hct}_{\text {pre }}$ and $\mathrm{HbF}_{\text {pre }} \%$ and $0.3 \mathrm{~mL}$ ten to fifteen minutes afterward for $H b F_{\text {post }} \%$.

\section{RESULTS}

The mean $( \pm \mathrm{SD}) \mathrm{CBV}$ measured by the TDD technique was $1.72 \pm 0.76 \mathrm{~mL} / 100 \mathrm{~g}$ (median: $1.49 \mathrm{~mL} / 100 \mathrm{~g}$, range: $0.34-$

Table 1. Results of the study

\begin{tabular}{|c|c|c|c|c|c|c|c|}
\hline Infant No. & $\begin{array}{c}\text { Gestational age } \\
\text { (weeks) }\end{array}$ & $\begin{array}{c}\text { Postnatal age } \\
\text { (days) }\end{array}$ & $\begin{array}{l}\text { Weight on the day } \\
\text { of measurement } \\
(\mathrm{g})\end{array}$ & $\begin{array}{l}\text { Correlation coeff., } r \\
\text { (IHI Vs. } \Delta \mathrm{C}_{\mathrm{ICG}, \mathrm{tis}} \text { ) }\end{array}$ & $\begin{array}{c}\text { CBV } \\
(\mathrm{ml} / 100 \mathrm{~g}) \\
\end{array}$ & $\begin{array}{l}\mathrm{TCV}_{\mathrm{TDD}} \\
(\mathrm{ml} / \mathrm{kg})\end{array}$ & $\begin{array}{l}\mathrm{TCV}_{\mathrm{FHD}} \\
(\mathrm{ml} / \mathrm{kg})\end{array}$ \\
\hline 1 & 26 & 1 & 980 & 0.92 & 1.05 & 48.81 & 73.60 \\
\hline 3 & 27 & 26 & 1640 & 0.96 & 2.29 & 77.56 & 76.30 \\
\hline 4 & 26 & 1 & 1030 & 0.91 & 1.42 & 85.03 & 77.48 \\
\hline 5 & 41 & 1 & 3400 & 0.95 & 1.98 & 58.83 & 58.05 \\
\hline 8 & 23 & 1 & 670 & 0.86 & 1.49 & 114.82 & 56.33 \\
\hline 9 & 30 & 12 & 1615 & 0.93 & 1.36 & 61.73 & 51.16 \\
\hline 10 & 24 & 3 & 670 & 0.89 & 0.34 & 16.36 & 97.76 \\
\hline 11 & 28 & 2 & 830 & 0.97 & 1.03 & 55.16 & 61.36 \\
\hline 12 & 30 & 11 & 1033 & 0.97 & 1.19 & 41.74 & 57.05 \\
\hline 13 & 27 & 1 & 1020 & 0.90 & 2.25 & 140.55 & 88.57 \\
\hline mean $\pm \mathrm{SD}$ & & & & & $1.72 \pm 0.76$ & $70.80 \pm 32.54$ & $70.19 \pm 13.73$ \\
\hline $\begin{array}{l}\text { median } \\
\text { (range) }\end{array}$ & $\begin{array}{c}28 \\
(23-41)\end{array}$ & $\begin{array}{c}6 \\
(1-33)\end{array}$ & $\begin{array}{c}1030 \\
(640-3400)\end{array}$ & & $\begin{array}{c}1.49 \\
(0.34-3.32)\end{array}$ & $\begin{array}{c}61.73 \\
(16.36-140.55)\end{array}$ & $\begin{array}{c}67.23 \\
(51.16-97.76)\end{array}$ \\
\hline
\end{tabular}


$3.32 \mathrm{~mL} / 100 \mathrm{~g})$. The median and mean $T C V_{F H D}$ were 67.23 $\mathrm{mL} / \mathrm{kg}$ and $70.19 \pm 13.73 \mathrm{~mL} / \mathrm{kg}$, respectively (range: $51.16-$ $97.76 \mathrm{~mL} / \mathrm{kg}$ ), and the median and mean $T C V_{T D D}$ were 61.73 $\mathrm{mL} / \mathrm{kg}$ and $70.80 \pm 32.54 \mathrm{~mL} / \mathrm{kg}$ (range: $16.36-140.55 \mathrm{~mL} /$ $\mathrm{kg}$ ). A Bland Altman analysis (24) is shown in Fig. 5. The bias between the two methods was $0.61 \pm 34.34 \mathrm{~mL} / \mathrm{kg}$ (the $95 \%$ confidence interval: $-13.93-15.16 \mathrm{~mL} / \mathrm{kg}$ ) and the limits of agreement (2 S.D.) were $-68.07 \mathrm{~mL} / \mathrm{kg}$ and $69.30 \mathrm{~mL} / \mathrm{kg}$, respectively.

\section{DISCUSSION}

Our aim was to develop a method that could measure TCV soon after birth. This precluded the use of fetal $\mathrm{Hb}$ dilution, which can only be done at the time of blood transfusion and biotin labeled autologous red cell dilution, which takes several hours to obtain a result. In contrast the NIR monitor is simple to apply and the developed TDD method can be automated. As soon as venous access is established, the ICG can be injected and the result should be available within $20 \mathrm{~min}$.

The use of ICG. ICG has been used for clinical investigations such as measuring hepatic blood flow, testing liver function and measuring cardiac output for more than 40 years $(25$, 26). It is firmly bound to plasma proteins, excreted in bile in unconjugated form, and rapidly eliminated by the liver within $10-15 \mathrm{~min}$. ICG has been shown to be safe in adults (27) and when used in newborn and preterm infants $(4,8)$.

Validity of the TDD method. The Bland Altman plot in Fig. 5 shows a slight positive slope between the differences and averages of the $\mathrm{TCV}_{\mathrm{TDD}}$ and $\mathrm{TCV} \mathrm{FHD}_{\mathrm{FH}}$, which suggests that the TDD tends to overestimate for larger TCV (with respect to the overall average, $\sim 70 \mathrm{~mL} / \mathrm{kg}$ in Table 1) and underestimates for smaller TCV. While the bias was small, the TDD method has limited agreements with the FHD method as suggested by the limits of agreement. Although this could partly be due to inaccuracies inherent in the FHD method, the TDD method is also subject to its own limitations, some of which are applicable to NIR based methods in general (14). Firstly, the calcu-

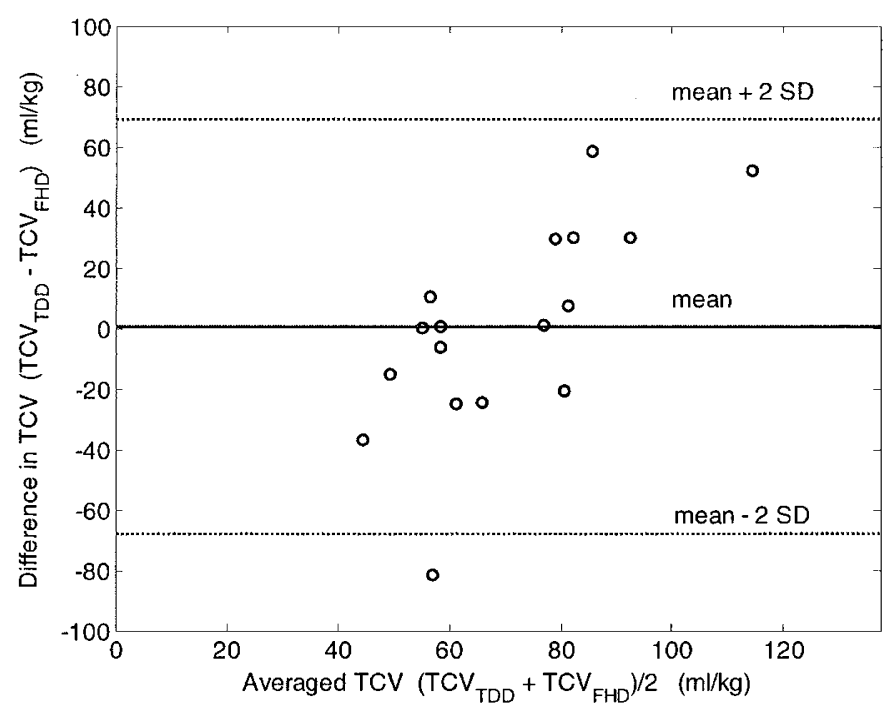

Figure 5. The Bland Altman plot: Bias of TCV obtained using the FHD and TDD methods. lation of $\mathrm{CBV}$ involves the use of a predefined constant known as the DPF as mentioned earlier. Depending on the location of the measurement site and the age of the subject, DPF can vary from 5.13 in infants to 6.26 in adults (15). It has been reported that DPF has a SD of approximately $15 \%$ among the same group of subjects $(14,15)$, accordingly, the accuracy of the measurements of CBV and TCV may also be affected. Secondly, the measured NIR data, whether from conventional difference spectroscopy or SRS, are all calculated assuming the tissues to be homogenous whereas in reality the probing area includes skin, skull, cerebral tissues, and cerebrospinal fluid. Thirdly, in the conversion from $t c H b$ to $\mathrm{CBV}$, another scaling factor, the Cerebral to Large Vessel Hematocrit Ratio is used to compensate for the reduced red cell content of blood in cerebral vessels compared with that in the large vessels (due to the Fahraeus effect) from which the blood sample was taken. The exact value of this scaling factor is still a subject of controversy. While a value of 0.69 was used here (20), another study has suggested a different value of 0.75 (28).

In this study the tissue water content and background absorption were assumed to be $90 \%$ and $22 \%$. Although these assumptions are supported by previously published estimates $(16,19)$, the actual values may be different and again are likely to vary between subjects, causing inaccuracies in the measurement of CBV and TCV. One future development of the TDD technique is to include the estimations of DPF and background absorption using a multi-wavelength spectrometer (e.g. a charge coupled device) and the second differential spectroscopy (16) technique.

The dose of ICG given to the infants was very small $(0.13-0.7 \mathrm{mg}$ or $0.13-0.7 \mathrm{~mL})$. The accuracy of the estimate of TCV is dependent upon the accuracy with which this small dose is drawn up and administered. Despite these potential pitfalls, NIR based methods are an attractive clinical option given the inexpensive, noninvasive and portable nature of the systems $(5-11,14,16,19)$. The NIR methods in measuring TCV and CBV in the newborn have not however previously been directly compared with another method.

Data from 7 of the 25 babies recruited had to be excluded because of problems with the NIR based method. The NIR signal is easily affected by body movements that led to loss of data from 5 babies. The failure to see clearly the first circulation of the tracer that occurred in two studies was probably due to slow injection of the ICG. We think that these problems were accentuated because the technique was being learned and that the exclusion rate would be unlikely to be so high again.

It can be seen from Table 1 that $T C V_{T D D}$ results are less close to their $T C V_{F H D}$ counterparts when the correlation coefficients between $I H I$ and $\Delta C_{I C G \text {,tis }}$ are lower than 0.9 , most notably in infant 10 . These circumstances may reflect "noisy" signals caused by movement artifacts or invalid assumptions being made about the measurement site. This correlation coefficient may therefore have the potential of assessing the reliability of the results obtained using the TDD method.

The infants included in this study were all clinically stable with normal $\mathrm{pH}$ although all needed some form of ventilatory support. Indocyanine green is bound to albumin and thus the method should be more accurately regarded as measuring the 
“albumin space." In a clinical situation where there is leakage of albumin from the vasculature this will lead to overestimation of TCV. It is hoped that by using only the first four minutes of the dilution curve (Fig. 3) in the calculation of $\mathrm{C}^{0}{ }_{I C G, b l}$ ) that this effect will be minimized, but the possibility that it will contribute error will need to be considered as the technique is extended to the study of less stable infants.

Comparison with existing techniques. In choosing a standard method against which to compare the new technique, we rejected the biotin labeled autologous red cell dilution method, which was unlikely to be acceptable to the parents of our babies. Direct comparison with classic ICG dilution would have limited potential recruits to those with an arterial line and introduced the complication of precisely timed repeated sampling to construct a wash out curve (4). Hudson et al. (3) have previously successfully used red cell volume measured by FHD as the standard method in their evaluation of the biotin method in the newborn. It is a safe method that should yield reliable results and was acceptable to parents and staff. Although the SD of the measurements of TCV using the new method was particularly wide it was nonetheless also wide at $70.19 \pm 13.73 \mathrm{~mL} / \mathrm{kg}$ using FHD.

Studies of TCV of newborn infants are limited and previous measurements have all reported a wide range of results. Mollison et al. studied 28 full term healthy babies within $24 \mathrm{hrs}$ of birth using radio labeled albumen and reported that the mean TCV was $84.7 \mathrm{~mL} / \mathrm{kg}$ (range $68.5-100.3 \mathrm{~mL} / \mathrm{kg}$ ) (29). Leipala et al. used FHD and studied 23 preterm infants (26-31 wks gestation) needing blood transfusion and reported that the mean TCV was $70 \pm 9 \mathrm{~mL}$ in appropriately grown and $70 \pm$ $16 \mathrm{~mL}$ in small for gestation babies (30). Anthony et al. measured the plasma volume in 18 preterm and full term infants (median gestation $30 \mathrm{wks}$ ) by dye dilution technique using ICG and reported the median plasma volume of 40.9 $\mathrm{mL} / \mathrm{kg}$ (range: $21.4-106.3 \mathrm{~mL} / \mathrm{kg}$ ) (4). Hudson et al. measured the pretransfusion red cell volume in 20 infants by FHD (25-34 wk gestation) and reported the median red cell volume of 26.3 $\mathrm{mL} / \mathrm{kg}$ (range: $13.1-41.5 \mathrm{~mL} / \mathrm{kg}$ ) (3). They also measured the paired red cell volume by FHD and biotin labeling red cells and found strong correlation between the two methods $(n=13, \mathrm{r}=$ 0.989) (3). The Bland Altman analysis of our comparison of $\mathrm{TCV}_{\mathrm{TDD}}$ with $\mathrm{TCV}_{\mathrm{FHD}}$ measurements showed a small overall bias but the range of the results using TDD was wider than using other methods.

The CBV obtained in this study is similar to that previously reported in infants using another NIR technique with oxygen tracers, i.e. $1.90 \pm 0.34 \mathrm{~mL} / 100 \mathrm{~g}$ (corrected for the $D P F(780$ $n m)=5.13$ used here) (9) but higher than that obtained in adults using NIR, blood sampling and ICG tracers, i.e. $1.1 \pm$ $0.39 \mathrm{~mL} / 100 \mathrm{~g}(10)$. The CBV obtained in this study is comparatively lower than that obtained from a SPECT study, i.e. $4.81 \pm 0.37 \mathrm{~mL} / 100 \mathrm{~g}(28)$. The discrepancy could be due to the fact that NIR techniques measure in the volume of tissue through which the photons have traveled, including the scalp, bone, cerebrospinal fluid, gray and white matter. The skin and scalp, which have less blood content than the gray matter, may account for about $10 \%$ of the total absorption while the cerebrospinal fluid is mainly transparent and does not absorb much light. It has been reported that the regional CBV is lower in white matter than in gray matter (31). Our result agrees with theoretical predictions (32) that photons travel deeper into the neonatal brain and spend more time in the white matter, resulting in a lower average CBV.

Comparison with the pulse dye densitometry. Aoyagi et al. introduced a NIR based technique known as Pulse DyeDensitometry (PDD) to measure TCV (21) in adults and the method has been implemented in the dye densitogram analyser (DDG-2001, Nihon Kohden Co., Tokyo, Japan). This technique involves the injection of ICG and the measurement of its concentration in arterial blood using an adaptation of the pulse oximetry technique with either a nose or finger probe. In adults, the technique has been shown to correlate well with results obtained from the radioisotope-based techniques (33). Comparing our TDD method with the PDD method, the former method can provide both CBV and TCV with one injection of ICG while PDD can only measure TCV. Both techniques of course provide data on liver function via measurement of the ICG clearance rate. The major difference between the PDD and TDD methods is that the PDD is based on measurements in the arterial blood while the TDD method is based on tissue blood measurements. The PDD technique requires first of all the ability to detect a pulsatile arterial signal, and as a result, cannot be applied to patients with poor peripheral circulation giving rise to weak arterial signals (33). Also, the temporal resolution of the PDD system is limited by the heart rate whereas the current NIRO-300 can sample at $6 \mathrm{~Hz}$.

In conclusion, the TDD method introduced here has the potential to be a useful cotside tool for studying TCV and $\mathrm{CBV}$. As presently described it could be used in combination with other noninvasive methodologies in the study of circulatory adaptation in the period shortly after birth. Further improvement and studies to determine the limits of its absolute accuracy and repeatability are needed before its role in the clinical setting can be assessed.

\section{APPENDIX}

It has been reported that the preterm neonatal brain consists of $90 \%$ water (19) and the background optical absorption in cerebral tissues account for approximately $30 \%$ of the total absorption coefficient $(16,17)$. This background absorption includes all sorts of chromophores found in tissue including melanin, lipids and etc. The background absorption appears as a constant offset in the absorption coefficient over all wavelengths. In general in the NIR spectroscopy, we can consider 5 major chromophores in tissue: oxy-Hb, deoxy-Hb, ICG, water and background substances. Based on the modified BeerLambert law, we can write:

$$
\begin{aligned}
\mu_{a}\left(\lambda_{1}\right)=\epsilon_{H H b, 1} C_{H H b} & +\epsilon_{H b O_{2}, 1} C_{H b O_{2}} \\
& +\epsilon_{I C G, 1} C_{I C G}+\epsilon_{H_{2} O, 1} C_{H_{2} O}+b \quad \text { (Equation 1) }
\end{aligned}
$$

where $\hat{\mu}_{\mathrm{a}}\left(\lambda_{1}\right)$ is the absorption coefficient at wavelength $\lambda_{l}, \epsilon$ is the specific extinction coefficient of a chromophore, $C$ is the concentration of the chromophore and $b$ is a constant absorp- 
tion coefficient representing the background absorption. In matrix form,

$$
\boldsymbol{\mu}_{a}=\epsilon \mathbf{C}+\mathbf{B}
$$

where

$$
\boldsymbol{\mu}_{a}=\left[\begin{array}{l}
\mu_{a}\left(\lambda_{1}\right) \\
\mu_{a}\left(\lambda_{2}\right) \\
\mu_{a}\left(\lambda_{3}\right)
\end{array}\right] \quad \mathbf{C}=\left[\begin{array}{l}
C_{H H b} \\
C_{H b O_{2}} \\
C_{I C G} \\
C_{H_{2} O}
\end{array}\right] \quad \mathbf{B}=\left[\begin{array}{l}
b \\
b \\
b
\end{array}\right]
$$

Using published data and data measured in our laboratory for the specific extinction coefficients for $\mathrm{Hb}$ (34), ICG and water $\left(\lambda_{1}=778 \mathrm{~nm}, \lambda_{2}=813 \mathrm{~nm}, \lambda_{3}=850 \mathrm{~nm}\right)$ :

$$
\begin{aligned}
\boldsymbol{\epsilon}=\left[\begin{array}{llll}
\epsilon_{H H b, 1} & \epsilon_{H b O_{2}, 1} & \epsilon_{I C G, 1} & \epsilon_{H_{2} O, 1} \\
\epsilon_{H H b, 2} & \epsilon_{H b O_{2}, 2} & \epsilon_{I C G, 2} & \epsilon_{H_{2} O, 2} \\
\epsilon_{H H b, 3} & \epsilon_{H b O_{2}, 3} & \epsilon_{I C G, 3} & \epsilon_{H_{2} O, 3}
\end{array}\right] \\
=\left[\begin{array}{cccc}
1.1566 & 0.7229 & 133 & 1.715 \times 10^{-7} \\
0.7941 & 0.9416 & 192 & 1.462 \times 10^{-7} \\
0.7861 & 1.1596 & 32 & 2.978 \times 10^{-7}
\end{array}\right]
\end{aligned}
$$

In this paper, we consider the background absorption to account for $22 \%$ of $\hat{\mu}_{a}$ at all wavelengths and can be approximated by:

$$
b=0.22 \times \mu_{a}(813 \mathrm{~nm})
$$

(Equation 3)

The NIRO-300 spectrometer used in these studies includes a measurement at a wavelength at $813 \mathrm{~nm}$. The effect of the background absorption can be minimized by subtracting it from the calculated total $\mu_{a}$. Equation 1 is now rewritten as:

$$
\hat{\boldsymbol{\mu}}_{a}=\boldsymbol{\mu}_{a}-\mathbf{B}=\boldsymbol{\epsilon} \mathbf{C}
$$

(Equation 4)

where represents the absorption estimated to arise from the four known chromophores. The NIRO-300 spectrometer uses a measurement of attenuation gradients at 3 wavelengths to calculate $\hat{\boldsymbol{\mu}}$. The concentrations of the 3 chromophores $(\mathrm{HHb}$, $\mathrm{HbO}_{2}$, and ICG) can then be estimated using least square minimization.

$$
\hat{\mathbf{C}}=\boldsymbol{\epsilon}_{\mathbf{R}}{ }^{-1} \hat{\boldsymbol{\mu}}_{\mathrm{a}}
$$

(Equation 5)

where $\hat{\mathrm{C}}$ is the estimated concentrations and $\epsilon_{\mathrm{R}}{ }^{-1}$ is the inverse of the reduced matrix. Both matrices account for only $\mathrm{HHb}$, $\mathrm{HbO}_{2}$, and ICG:

$$
\hat{\mathbf{C}}=\left[\begin{array}{l}
\hat{C}_{H H b} \\
\hat{C}_{H b O_{2}} \\
\hat{C}_{I C G}
\end{array}\right] \quad \boldsymbol{\epsilon}_{\mathbf{R}}=\left[\begin{array}{lll}
\boldsymbol{\epsilon}_{H H b, 1} & \boldsymbol{\epsilon}_{H b O_{2}, 1} & \boldsymbol{\epsilon}_{I C G, 1} \\
\boldsymbol{\epsilon}_{H H b, 2} & \boldsymbol{\epsilon}_{H b O_{2}, 2} & \boldsymbol{\epsilon}_{I C G, 2} \\
\boldsymbol{\epsilon}_{H H b, 3} & \boldsymbol{\epsilon}_{H b O_{2}, 3} & \boldsymbol{\epsilon}_{I C G, 3}
\end{array}\right]
$$

The estimated concentration based on a 3-wavelength SRS spectrometer becomes:

$$
\hat{\mathbf{C}}=\boldsymbol{\epsilon}_{\mathrm{R}}{ }^{-1} \hat{\boldsymbol{\mu}}_{\mathrm{a}}=\boldsymbol{\epsilon}_{\mathrm{R}}{ }^{-1} \boldsymbol{\epsilon} \mathrm{C}
$$

Solving the simultaneous equations results in,

$$
\begin{aligned}
& \hat{C}_{H H b}=C_{H H b}+90.93 \times 10^{-9} C_{H_{2} O} \\
& \hat{C}_{\mathrm{HbO}_{2}}=C_{\mathrm{HbO}_{2}}+213 \times 10^{-9} C_{\mathrm{H}_{2} \mathrm{O}} \quad(\mu \mathrm{mol}) \\
& \hat{C}_{I C G}=C_{I C G}-0.66 \times 10^{-9} C_{\mathrm{H}_{2} \mathrm{O}}
\end{aligned}
$$

(Equation 7)

It can be seen from Equation 7 that the estimated concentrations are affected by the volume assumed for the water content of the tissue. Assuming 90\% water in neonatal brains (recall $100 \%$ pure water corresponds to 55.4 Molar), $C_{H 2 O}$ can be calculated

$$
C_{\mathrm{H}_{2} \mathrm{O}}=0.9 \times 55.4 \mathrm{~mol}=49.86 \times 10^{6} \quad(\mu \text { molar })
$$

(Equation 8)

Substituting Equations 7 and 8 into the expression for $\Delta I H I$, we obtain:

$$
\Delta I H I=\frac{\Delta C_{I C G}}{t c H b+15.15}
$$

(Equation 9)

The above result shows that if no correction is made for the effects of water absorption, then using $\Delta I H I$ and $\Delta \mathrm{C}_{I C G}$ to estimate $t c H b$ will lead to an over-estimate of $15.15 \mu$ molar. To compensate for this offset, in this paper the value obtained from the expression $t c H b=\Delta \mathrm{C}_{I C G} / \Delta I H I$ has been corrected by subtracting $15.15 \mu \mathrm{mol}$. To assess the sensitivity of the results obtained to the assumptions made in these calculations, we have looked at the sensitivity of the correlation coefficient and the mean difference between $\mathrm{TCV}_{\mathrm{TDD}}$ and $\mathrm{TCV}_{\mathrm{FHD}}$ over a range of different values of water content $(70 \%$ to $95 \%)$ and assumed background absorption contribution (5\% to $35 \%)$. A high correlation coefficient $(>0.8)$ was maintained with water content variation over the whole range ( $70 \%$ to $95 \%)$ and for background absorptions of $<35 \%$. The mean difference was as high as $42.09 \mathrm{~mL}$ with the rather un-physiologic assumptions of a background absorption $=5 \%$ and water content $=70 \%$. The mean difference changed by $-1.68 \mathrm{~mL}$ per $\%$ change in background absorption and by $-0.70 \mathrm{~mL}$ per \% for the water content. The minimum mean difference $(0.0219 \mathrm{~mL})$ was obtained when the water content $=85 \%$ and the background absorption $=24 \%$, close to the values of $90 \%$ and $22 \%$ used in this paper and derived from independently measured data $(16,19)$.

Acknowledgments. The authors would like to thank all the patients and their parents participated in this study, medical and nursing staff in the NICU and the department of hematology Homerton University Hospital for their cooperation, the Wellcome Trust for funding (TSL), and Hamamatsu KK for providing a spectrometer.

\section{REFERENCES}

1. Narendra A, Aitchison TC, Beckett C, Coutts J, Holland BM, Jones JG, Kyle BM, Turner TL, Wardrop CA 1998 Can we assess the preterm infant's blood volume status clinically. Proc Royal Coll Paediatr Child Health 2:61

2. Shippy CR, Appel PL, Shoemaker WC 1984 Reliability of clinical monitoring to assess blood volume in critically ill patients. Crit Care Med 12:107-112 
3. Hudson IR, Cavill IA, Cooke A, Holland BM, Hoy TG, Trevett D, Turner TL Wardrop CA 1990 Biotin labelling of red cells in the measurement of red cell volume in preterm infants. Pediatr Res 28:199-202

4. Anthony MY, Goodall SR, Papouli M, Levene MI 1992 Measurement of plasma volume in neonates. Arch Dis Child 67:36-40

5. Matcher SJ, Kirkpatrick P, Nahid K, Cope M, Delpy DT 1995 Absolute quantification methods in tissue near infrared spectroscopy. Proc SPIE 2389:486-495

6. Suzuki S, Takasaki S, Ozaki T, Kobayashi Y 1999 A Tissue Oxygenation Monitor using NIR Spatially Resolved Spectroscopy. Proc SPIE 3597:582-592

7. Edwards AD, Wyatt JS, Richardson C, Delpy DT, Cope M, Reynolds EO 1988 Cotside measurement of cerebral blood flow in ill newborn infants by near-infrared spectroscopy. Lancet 2:770-771

8. Patel J, Marks K, Roberts I, Azzopardi D, Edwards AD 1998 Measurement of cerebral blood flow in newborn infants using near infrared spectroscopy with indocyanine green. Pediatr Res 43:34-39

9. Wyatt JS, Cope M, Delpy DT, Richardson CE, Edwards AD, Wray S, Reynolds OR 1990 Quantitation of cerebral blood volume in human infants by near-infrared spectroscopy. J Appl Physiol 68:1086-1091

10. Hopton P, Walsh TS, Lee A 1999 Measurement of cerebral blood volume using near-infrared spectroscopy and indocyanine green elimination. J Appl Physiol $87: 1981-1987$

11. Cope M, Delpy DT 1988 A system for the long term measurement of cerebral blood and tissue oxygenation in newborn infants by near infrared transillumination. Med Biol Eng Comput 26:289-294

12. Phillips HM, Holland BM, Abdel-Moiz A, Fayed S, Jones JG, Turner TL, Wardrop CA, Cockburn F 1986 Determination of red-cell mass in assessment and management of anaemia in babies needing blood transfusion. Lancet 8464:882-884

13. De Visscher G, van Rossem K, van Reempts JV, Borgers M, Flameng W, Reneman RS 2002 Cerebral blood flow assessment with indocyanine green bolus transit detection by near-infrared spectroscopy in the rat. Biochem Physiol 132:87-95

14. Delpy DT, Cope M 1997 Quantification in tissue near-infrared spectroscopy. Philos Trans R Soc Lond B Biol Sci 352:649-659

15. Duncan A, Meek JH, Clemence M, Elwell CE, Fallon P, Tyszczuk L, Cope M, Delpy DT 1996 Measurement of cranial optical path length as a function of age using phase resolved near infrared spectroscopy. Pediatr Res 39:889-894

16. Matcher SJ, Cope M, Delpy DT 1993 Use of the water absorption spectrum to quantify tissue chromophore concentration changes in near-infrared spectroscopy. Phys Med Biol 38:177-196

17. van der Zee P 1993 Measurement and modelling of the optical properties of biological tissues in the near infrared. PhD thesis, University of London

18. Woodward HQ, White DR 1986 The composition of body tissues. Br J Radiol 59:1209-1219

19. Cooper CE, Elwell CE, Meek JH, Matcher SJ, Wyatt JS, Cope M, Delpy DT 1996 The non-invasive measurement of absolute cerebral deoxyhemoglobin concentration and mean optical path length in the neonatal brain by second derivative near infrared spectroscopy. Pediatr Res 39:32-38
20. Lammertsma AA, Brooks DJ, Beaney RP, Turton DR, Kensett MJ, Heather JD, Marshall J, Jones T 1984 In vivo measurement of regional cerebral haematocrit using positron emission tomography. J Cereb Blood Flow Metab 4:317-322

21. Iijima T, Aoyagi T, Iwao Y, Junichi M, Fuse M, Kobayashi N, Sankawa H 1997 Cardiac output and circulating blood volume analysis by pulse dye-densitometry. J Clin Monit 13:81-89

22. Picker O, Wietasch G, Scheeren TW, Arndt JO 2001 Determination of total blood volume by indicator dilution: a comparison of mean transit time and mass conservation principle. Intensive Care Med 27:767-774

23. Kutlar A, Kutlar F, Wilson JB, Headlee MG, Huisman TH 1984 Quantitation of hemoglobin components by high-performance cation-exchange liquid chromatography: its use in diagnosis and in the assessment of cellular distribution of hemoglobin variants. Am J Hematol 17:39-53

24. Bland JM, Altman DG 1986 Statistical methods for assessing agreement between two methods of clinical measurements. Lancet 1986 8:307-310

25. Caesar J, Shaldon S, Chiandussi L, Guevara L, Sherlock S 1961 The use of indocyanine green in the measurement of hepatic blood flow and as a test of hepatic function. Clin Sci 21:43-57

26. Emmanouilides GC, Moss AJ, Monset-Couchard M, Marcano BA, Rzeznic B 1970 Cardiac output in newborn infants. Biol Neonat 15:186-197

27. Hope-Ross M, Yannuzzi LA, Gragoudas ES, Guyer DR, Slakter JS, Sorenson JA, Krupsky S, Orlock DA, Puliafito CA 1993 Adverse reactions due to indocyanine green. Ophthalmology 101:529-533

28. Sakai F, Nakazawa K, Tazaki Y, Ishii K, Hino H, Igarashi H, Kanda T 1985 Regional cerebral blood volume and haematocrit measured in normal human volunteers by single-photon emission computed tomography. J Cereb Blood Flow Metab 5:207-213

29. Mollison PL, Veall N, Cutbush M 1950 Red cell and plasma volume in newborn infants. Arch Dis Child 25:242-253

30. Leipala JA, Talme M, Viitala J 206A 1999 Determination of neonatal blood volume with the haemoglobin subtype method in appropriately grown and growth retarded preterm infants. Pediatr Res 45:206A

31. Ladurner G, Zilkha E, Iliff D, Du Boulay GH, Marshall J 1976 Measurement of regional cerebral blood volume by computerised axial tomography. J Neurol Neurosurg Psychiatry 39:152-158

32. Okada E, Delpy DT 1996 The effect of overlying tissue on NIR light propagation in neonatal brain. OSA TOPS on Advances in Optical Imaging and Photon Migration $2: 338-343$

33. Imai T, Mitaka C, Koike A, Ohki S, Isa Y, Kunimoto F 2000 Accuracy and repeatability of blood volume measurement by pulse dye densitometry compared to the conventional method using ${ }^{51} \mathrm{Cr}$-labeled red blood cells. Intensive Care Med 26:1343-1349

34. Matcher SJ, Elwell CE, Cooper CE, Cope M, Delpy DT 1995 Performance comparison of several published tissue near-infrared spectroscopy algorithms. Anal Biochem 227:54-68 